R. Iftstórta, Săo Paulo, n. 129-131, p. 19-30, ago.-dez/93 a ago.-dez./94.

\title{
O FANTASMA DA UNIDADE CULTURAL NA METÁFORA PALINÓdICA DO BRASILEIRO ALEMÃO
}

\author{
Sergio Bairon*
}

RESUMO: O fantasma da unidade cultural na metáforn palinódica do brasileiro alemão, apresenta-se como uma projeçâo da história da "cultura européia" no Sul do Brasil. A crença de que aqui reproduziu-se, en micro.regionalidades, uma Alemanha ou uma Itólia, apresentase de forma muito clarn ainda neste final de século. O presente desafio para a compreensão desla histớin percorre dois polêmicus camiulos. De utI) Jado, a psicanílise cultural, que pode possibilitar, não uma "Ierapia du.sucial" como na proposıa culturalista norte-americana, mas sim, uma explornçio da psicanálise enţuanto uma leoria da linguagem. De outro laub, uma hermenêutiç culıural, que tem por esco|xo a islentificaçĩo de significaçōes universais, presentes em tais regionalidades. Este lexto não se eny̧uadra nos caminhos obnubilosos da atual História das Mentatiundes, no que diz respeitu à Psicanálise ou à hermenêutica Cultural.

PALAVRAS-C:lIAVE: fantasma, metáfora, palinúdico, outro, denegaçăo

A história da colonização e da cultura alemā no Sul do Brasil tornou-se uma grande narraliva cpopéica que përpasssa, liundamentalmente, por uma mescla dos conceilos de raça e naçăo'. Inspirados nesla semântica devemos levantar uma

* Doutor ell Ilistúria Soxial pela FFL.C.IJ/USP e Pös-doutorando na Iniversidnde Livre de Berlim.

1 "A Hiskória da Colonizaçâo é um hymno de louvor a esses intrépidos pioneiros que em trabathos e lutas eslorģados, mais to yue permilia a forģa humana, nfio desanimaram, nem nas situnģ̄es mais diffíceis yut se possa imaginar, lançando os alicerces de um monumen-

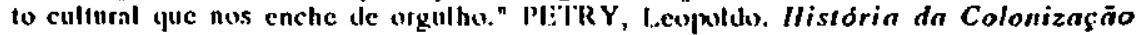

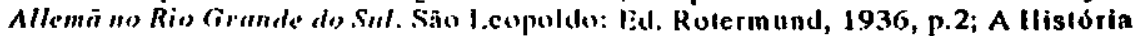
da Colonizagăo havia se tornado uma verdicleira epopéia, na cual as atitudes heróicas de toda uma comunidade garantiram a saga do colono alemåo. Engana-se, porém, ayuele que pensar yuc existeon sujcilos históricos de numes-próprios bem definidos em lal discursu. Nesle discurso, " sujeito da narrativa é o colono, símbolo da coumunidade, o heríi é a nòni mo e define-sc na relaģoo de qualyuer colono com sua "nova" Ileimat: "(Inde as palmcirns larfalhan, onde o sabin canta, onde da capelinha da colina " sinu sua. ondc a colono planta, ara e gradein, onde entre as folhas verdes escuras a laranja aparece madura, onde a sombra das palmeiras colocava obcrộs. Ali é minha pairia. mev lurtâo Rio-Grandense. Onde o Dois Irmåos nos saúda ulhanclo do nurte para nús, o quilombo e o sapucaia, resplandecentes nos 
BAIRON, Stgio. O fantasma da unidade cultural na metafora palinódica du brasileiro alemás.

série de questôes: qual o motivo úa cultura da região alemã através de seus textos históricos remeter-se onticamente à Alemanha? Qual a razão da contínua existencia de um discurso denegalório de ludo que possa apresentar uma alteridade do alemāo? Ou, porque o discurso incenlivado por conceilos nacionalistas e deterministas ${ }^{3}$ persistiu na homogeneizaçĩo Je todo elemento cultural regional?

As marcas da diversidade cultural que até os dias de hoje pretendem identificar o Sul enquanto, não só testemunha, mas verdadeiro reduto civilizador-folclórico da cullura européia, podem ser compreendidas como resultado da construção de um longo discurso fantasmálico-racista que se

conduciam ao descanso onde umn colinn ensolarada ao longo da esiradn, as casas nos acenam, two limpas e brilhantes, onde o jardim as cerca como laiza florida, ali e patria, meu torrjo Rio-Grandense. Onde o campo se espraia tăo solitírio e verde." Citado em MÜLLER, T.L. Colônian Alemẽ - 160 Anos de Histórin. Caxias do Sul: Editorn Universidade de Caxias do Sul, 1984, p.116-118. Todos depoimentos historiograficos th chamadh colönia alema do Sul do Brasil, sitoam-se no senticto de pivileginr a unidade do significado, o estilu sujeito-objeto, as noçaes ite progressu e de resgate da Ilistória "tal qual ezistiu": "wie es eigentlich gewessem". Próximo de Leopoldo von Ranke a história seria o "res gestae", o conhecimento um rellexo da vertade e o histurinctur o sujeito imparcial do conhecimento. Sem nenhuma reflexío tedrica ou filosofica, os fatos surgem dos tocumentos de uma forma objetiva e positiva. $A$ inspiraçấ, sem dúvida, vem dis ciências naturais, onde preponderava a possibilidade do conbecimento tutalizanle, na generalização de progresso social e ecunómico da Colônin Alems. Náo acreditamos que a atual llistória dins Mentalidades francesa tenha rompick profundamente com tais princípios.

2 Com exceçáo dus Irabalhos de Gïnler Weimer, Walter Kixh c outros poucos que pesquisaram, de alguma forma, a cultura regional alemả do Sul do Brasil, a grande maioria da bibliografia, refere-se a Alemanha de modo a trala-la como uma unica representaçăo cultural. Ver SANT'ANNA, Sérgio Bairun Blanco. A Mistórin Palinódica. I'ese de doutoramento apresentada no Departamento de Ilistória da liliLCII/USP, 1991 (mimeo.).

3 O problema básico do discurso nacionalista e yue tantasmagotiza uma coerència cullural que năo está presente no univetso simbúlico alem hón. A narrativa epopeica demonstra ter sua origem no caminho traçado anteriormente pela Liga Pan-germânica: "A Liga Pan-geranaica, portanto, náo só era partidlírin de uma Grosscleulschland, mas também de uma eatidace que incluiria todos os alemhes do munch, não importando o país cm yise vivessem. Esta comunidade seria prissivel mirye a nacionalidade, pata o alemño, é obtida por direilo de sangue e năo pelo fato de ter nascido na Alemanha. Neste sentido o cidadăo pode ser vinculado a um Estack, mas nño no nacional. Por isso, nn concepstoo Pan-germá. -ica, todos os alemáes e descendentes em lodo o mundo, poderiam formar uma unidade ancional sem se constitúrem, necessariamente, em traidores dos estadus dus quais são cidadhos. E, assim sendo, trabalharem para lornar a Alemanha uma forte potência mundial, seja abrigando mercados para indtisıria c comercio alemães, sejn Jivulganck a

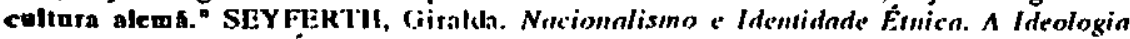

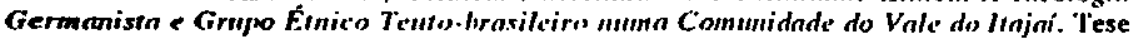
de Dontoramenlu apresenlada au Departamenlo de C'iências Socinis da FIFLCII/LISI, 1976, (mimeo.), p.45-46. 
R. Hlstórk, STĩo Paulo, n. 129-131, p. 19-30, ago-dez/93 a ago.dez./94.

construiu desde o final do século XIX. Estes fantasmas ${ }^{4}$ de um Grande Outro Epopéico ${ }^{5}$, baseados em vários e dislantes horizontes históricos, aparecem de forma narrativa como uma encenação imaginária, na qual o sujeito do discurso situa-se, primordialmente, na realizaçĩo de anseios identitário-regional-cultural. Como que num sonho diurno", o alemão do Sul só é capaz de relembrar seu passado passando por significantes da identidade coleliva que é fornecida pela sua imaginária páIria-māe..Alravés desıa idealização, nas colônias alemãs do Sul do Brasil, ascendeu, com cada vez mais força, uma narrativa epopéica.

Foi justamente em função da necessidade de reconstruir a imagem maior dá pátria-mãe (Alemanha) ${ }^{7}$ que o significante nacionalista "alemão" passou a ler mais influência na interpretação da cultura regional, do que as próprias significaçōes heterogêneas características do Sul do Brasil. No imáginário mnêmico institucional do teulo-brasileiro, a óptica germanista foi construindo-se resgalando desesperadamente qualquer dimensão de imagem que remetesse à pátria-mãe. $O$ imaginário cultural ${ }^{8}$, nesle instante, se apre-

4 O conceito fantasma, utilizado no presente texto, nfo pressupóe somente um recarso literárioformal. Pretende, pois, servir de argumento teúrico com o escopo de aproximar a psicańlise fretuliana da análise cultural. Os capítulus 03 e 04 de minha tese de dontomamento citadh acima, trabalhnm detalhadamente esta questão. Por ora, cabe salientar que fantasma 6 uma encenaç̧o discursivo-imaginária na qual o inclividuo está presente e atua alcançando de forma mais ou menus conforınadh a realizaçío de um anseio de identichde.

5 O Grande Outro Epopéico é conı resolvemus designar a articulaçăo discursiva que determinou - simbúlico cultural da chamada regiño alemâ do Sul do Brasil. Foi a convençáo discursiva por excelência yue passou a determinar um sentidu para a ordem simboltica regional. Como já dizia Roland Barthes "o Outru é toula a fila, o Outro é Social". BARTHES, R. O Rumor da Lingua. Sãu Panlo: Brasiliense, 1988, p.104. O Outro é, priorilariamente, funçăa No caso d coltura teuto-brasileirn, o Outro porde ser um cóligo de lingungem. O Outro Epoptico, enquanto cumpre um papel de realizaşío alucinntória do clesejo, é em totatitade a pátria-máe, $\boldsymbol{\epsilon}$ o todo coltural que resume as inúmerns ausências to din a dia. Enquanto funçâu, esta presente como referente estável, identificn e dá subsidios para a recurdaģão; e, como cứligo, o Outro Epoptico sastentese ma "defesa cho integrichule da língua alema".

6 Na narmativa do Grande Outro Epoptico, nâo há fronteiras entre us sunbos indivikual e coletivo. Próximo th conceituaçĩo fretıliann de sonho diurno, busca-se uma reconciliaçăo con uma identidade coletiva que, imagina-se, se perdeu. É no terreno imaginirio que se manifeato o sonbo diuno.

7 Recunstruir a pálrin-mãe lornuu-se o principxl objetivo dos descendentes dus imigrantes.

8 Há, entâu, uma preponderância de uma relaçióo fantasmática com a imagem de um semelhante: "alemão". No imaginário culiuml leutu-brnsileiro há sempre o Outro "alemåo" que remete to "eu". O "eu" teuto-brnsileiro serin originariamente o Outro "alem6́o". No imaginstro cultural náo só a identidade é imaginária, curno o próprio diverso de si. No imaginário cultural, há una identificnção com o que se desejnria transformar e que permanecea no logar da plenitude, on seja, da idenlizaçio. O teuto-brnsileiro vê como sua própria representaçăo outra imagem que ulo a sun, sentlo que nessi, é preciso renlş̣r, nāo há nada altan do que ele al colocoo: um camiahar de autosinulaģto alravés do Outro. Na consciència imaginária do teoto-brasileiro acaboo ocorrendo uma opusiçăo imediata entre a consciencia de si e do outra Neste sentida, o beuto-brasi- 
BAIRON, Sérgio. O fantasma th unidacte cultural na metáfora malinúdica do brasileiro alemão.

sentou através de um número sen-fim de imagens sob uma significação maior: "alemão". A cultura alemã reconsı́ói-se, lá no Sul do Brasil, como una colcha de retalhos que pretende, a todo custo, simular a si mesma.

A cultura alemã oferece, por un lado, o fundamento da possibilidade de identidade coletiva e, por outro, a relação do discurso fantasmálico de alemão com todo e qualquer objeto malerial do cotidiano. Na construção do fantasma de alemão, não aparece nem especificamente o objeto, nem unicamente a identificaçĩo, mas o cstabelecimento de uma relação narrativa profundamente imaginária entre ambos. Dizemos "profundamente imaginária" por que a inicialiva instilucional, governamental ou não, sempre deu-se através da necessidade de negar seu próprio mundo; e este discurso em prol da pátria-mãe acontecia numa temporalidade muito anterior à ascensão do discurso nazisıa que, como sabemos, ratificou aquele.

Acredilamos, então, que uma significação central sustentou a sobrevivência do universo simbólico teulo-brasileiro: a presença de uma ausência. Ou seja, a presença da pálria-mãe no imaginário tculo-brasileiro na forma de pequenas narrativas melafóricas já que no cámpo simbólico ela esıá ausente. Aquui, a rememoraçāo ${ }^{9}$ lornou-se o principal sustentáculo da memória coletiva articulando-se através da lógica de uma geografia imaginária, onde a imagem de qualquer "objeto alemāo" remete à pálıria-māe.

leiro, na procusa de si mesmo, acredita encontrar-se na narrntiva epopéica de sua colonizaçâto e perde-se em tudo que não é elin. No imaginário cullural da região houve entảo, uma preponde-

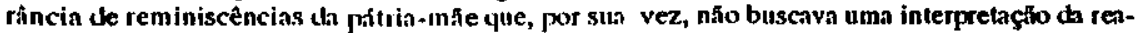
lidade cotiuliana, mas sim a montagèn e repetiçîo de fanlasmas culturnis. Os fantasmas, fruto de um pensamento essencialmentc imaginário, lêm uma relaçio amblgun com o discurso sobre a realidnde. Ao mesmo tem po em que ngem como defesn, simulinclo o que causa desprazer, preservam a memória coletiva (ha frustraçîo yue os originou, inclusive, numa via de recuperaçấ do passado. O imaginário cullural na leilura fantasmática encobre e produz compreensto concomiIantemente: "O fantasma 6 o avesso do munclu sempe presenle para suportí-lo". JURANVIL LE, Alain. Lncon e a Filosofin. Rio de Janeiro: Jorge Znhar, 1987, p.171.

9 Na narrativa fantasmálica, a pátria-mae yue acolhia seus filhos ficoll no passato, parntisacta, na mesma imagem aculhedora. Ial imagem, mssava a importar muito mais do que a miseravel condiş̧̃ó de grande parte da mopulaçño centro-entopéia no século pussado. Ver: WEIMER, G. A Arquite'tura da Imigrngäo Alemin. Porlo Alegre: Nobel, 1,983, p1).22 a 35; BONNEFON, Charles.

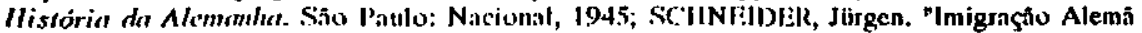
para o Brasil." IN: Colsyurio de lisludes Tieuto.brnsileiros, 3, Anais. Porto Alegre, 1974. Porlo Alegre: falitora da Universidacle, IIIR(iS, 1981), p.77-10\%). Rememuraç̃o c reminiscência aproximam-se no alo de recuperar clementus perdiches no encoudeanento da história simbólicos-cullu-

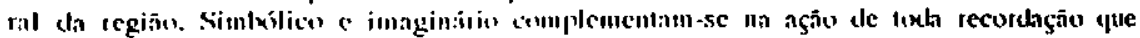

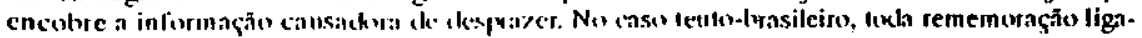

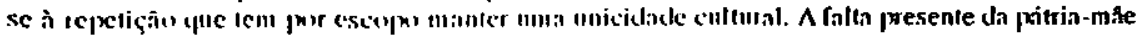

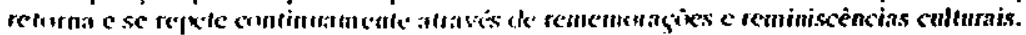


R. Iflstórta, Sţo Paulo, n. 129-131, p. 19.30, agu.-dez/93 a ago.-dez./94.

O fantasma é histórico a ao mesmo tempo ilusório. Seu aspecto ilusório o torna essencialmente subjelivo e, porlanto, imaginário. Seu caráter histórico surge alravés de um veio coletivo-cultural c, portanto, simbólico. Entre os regisıros imaginário e simbólico o lantasma defíne a relação do leulo-brasileiro com seu Grande Outro Cullural: a Alemanha.

Mas que Outro é este? O Outro necessariamente tem a ver com o outro, sempre no interior da arliculação que objelive uma vivência de identidade

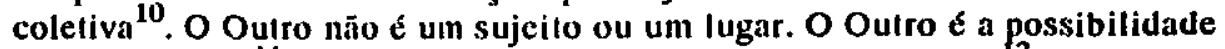
de significaçāo ${ }^{11}$, que arlicula-se tanlo no nívet imaginário ${ }^{2}$ quanto no simbólico ${ }^{13}$. Este discurso do Outro márca o leuto-brasileiro desde o nascimenlo.

O que preponderou enquanto lundamento da memória cultural regional, foi a ação delerminanle de peyuenos romances metafórico-idealizadores, responsáveis pela suslentação da exislência do lantasma pois quanto mais livermos conlalo com depoimentos. álbuns comemorativos elc. da chamada colónia alcmã do Sul do Brasil, mais nolaremos que a imagem que o leutobrasileiro loi construindo de si mesmo ¿. sem dúvida, sua própria, porém, essencialmente é a de um outro. Näo que tal falo deva remeler à questāo da

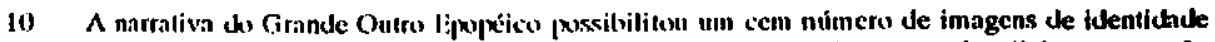

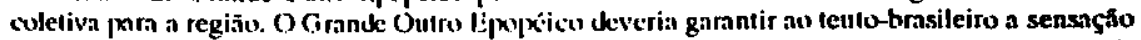

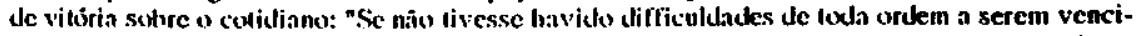

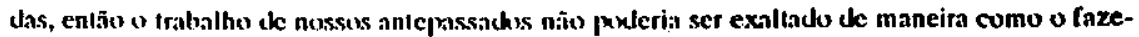
mos, nem tnmponco bes encheria de orguthe, pois somente ayuillo yue se conquista com sacrifficio é yue tem valur c somente un luta contra a ndversidnde o homem se lurna verchdeiramente grande senchy justamente ante essus lutas litanicas de nusssis anteprassadus que nos curva-

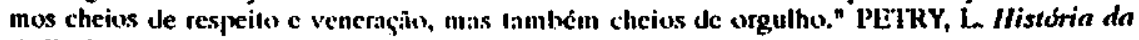

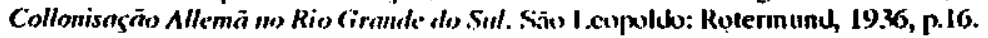

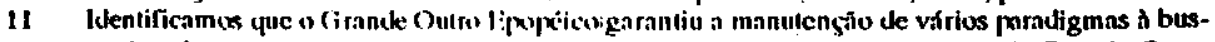
ca de reforģar instituiçies de cunho germanistio. Nesse aspecto, a narrativa do Gmnde Outro

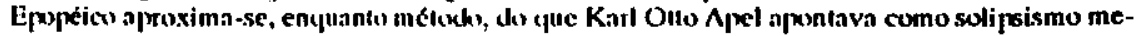
tódicu: "Hloy en dia mostratíamos sin slilicultad al pensacur solitario, que se crea obligndo a mantener ef solipsismo metixlicu yue ya pessujxunc un juego lingüístico priblico inctuso comn los argumentis yue para él mismo ckelen tener vilicter: por ejeinjolo, en el caso de la expresstón mernmente en la conciencie al juegu lingüístico pressupuestu hace depender el sentidu del angumento de hecho de que hxh o pxnsalwe estí meremente en la conciencia." APEL, K.O. La Trmoformnetion de In Filosofin. Mndrid: İditorial Taurus, 1986. v.II.p.301; tais questöes, porem, precisam ser melher aprofundactes.

12 É preciso se ter claro que descle a infîncia, o teuto-brasileiro, prepunderantemente até a lécada de 1940, constiluín seu muncho através chos clialetus uu do "huchukutsche". Pelo menos alé tal pe-

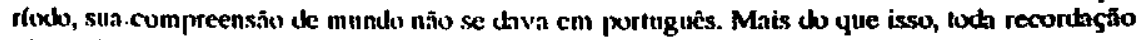
nhổ se thiva em purtuguês.

13 Sujeito nâo enyunnto contrapartida cte objeto a ser couphecilo e revetacto, mas encuanto a possibilidade de atuaçîu de uma lingungem que deixn seu munubu revelar-se. Neste sentido, 0 Grande Outro Epopeico, acima de tude, significa! 


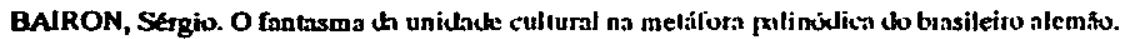

existencia ou não de uma falsa consciêncial ${ }^{14}$, ou a uma possível alienação cultural-polílico-social, mas indica a preponderância de uma consciência imaginária ${ }^{15}$, na medida yue se lem como fundiunento da própria identidade associaçōes ideais.

São estas questōes que obrigam aos teuto-brasileiros agradeccrem, freqũentemente, aos seus pais alemāes a cpopécia da origem da colonização. Se o teuto-brasileiro agradecer o suficiente nos pionciros cai ma melancolia c os fantasmas da epopéia perdein o polencial de suslento da identidade coletiva; mais que isto, a sensaçāo da plena idenlidade. Nesse trajeto, a compreensảo da grande saga, da epopéia e do conlínuo progresso económico do Sul passa de geraçāo a geraçāo, onde a peura angular é lanto a família dos nomes-próprios alemáes quanto, [undaméntalmenlc, ludo o que $\mathfrak{e}$ fániliar à pátria-māe ${ }^{16}$.

Na consıruçāo da epopéia teulo-brasileira, o Outro é o familiar, é ludo que se diz semelhanle ná montagem da própria odissćia da colonizaçäo. $O$ familiar causa o surgimento, alravés da linguagem fanlasmática, da possibilidade do sustento da identidade coleliva frente a leterogencidade cullural que se apreseniava na hisıória cullural da colonizaçãio.

Notamos que os exiremos prevalecem. $O$ diverso vai às úlimas conseqüéncias da estranheza c a geograliia percle o vínculo regional-cienlífico, predominando na conjuntura do inuginairio. Pedaços de "Alemanha" esı̃o em todas as partes do Sul do Brasil. Como não se consegue voltar às origens, cria-se a Heimat mesmo sem relornar para casa (Urheimat).

O fantasma mais presente yuc se consiruiu, ralificado nos anos $\mathbf{3 0}$ deste século, foi o da raça alemai ${ }^{17}$. Como sabemos em longas linhas, desue

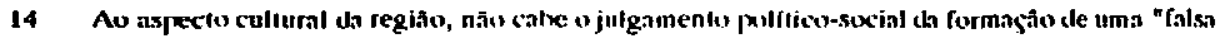
conscienncia". l'ercebenos yuc a consciência th "co" cullural teuk-brasileisu é essencialınente

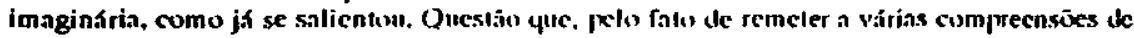

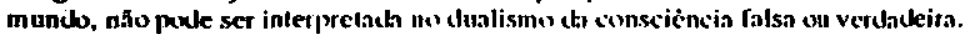

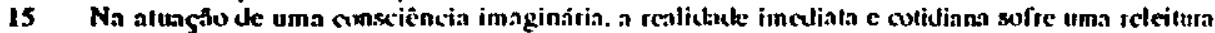
idealizaka, nunce é demnis lemlrar.

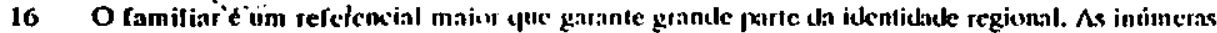

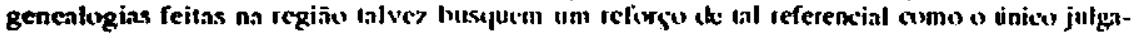

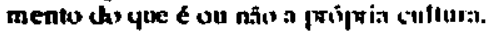

17 Ver I3OSSMAN. Reinalk, "Zur (k'ut,uh.hrasilianischen Misclsspache." Deutsch Nachrichten. Siu Paulo, 25 jan., 1958; I:RII:IJRIC 'IISi:N. A. "Wir der Deutsch in Suedtrasilien spricht." IN:

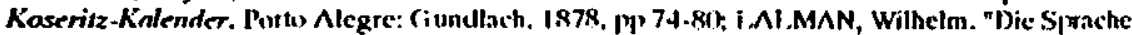

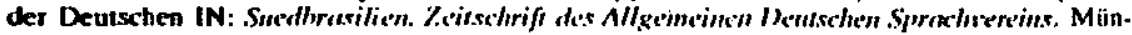
chen, n.09, 1905; 1.O1:W, IIrich. "Neus Sipachgull und neue Syrachunsilten bei Jen Deutsehen Rio grandes." IN: Serro Post-Kalender, ljuí. Serrann, 1927.jp.97-1117; OHI:RACKI:R, Cawlix

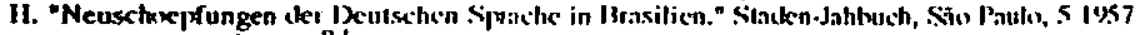

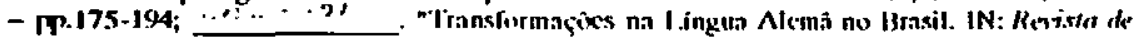


R. IItslórtn, Situ l'aulo, n. 129-131, p. 19-30, ago.-dez/93 a agu-dka_/94:

o século XIX, o posilivismo comleano, o darwinismo social e o evolucionismo de Spencer assumiram uma importante posição na interpretaçāo políticocullural ocidental, inclusive, junto da imtelligentsia brasileira. O evolucionismo social teve por escopo achar um sentido para as diferenças entre as sociedades humanas no decorrer da história. Através dos princípios evolucionisłas sociais, a clile européia criou a possibilidade de justificar a expansĩo mundial do capilalisıno, procurando comprovar a exisıéncia de superioridades naturais do curopeu em relaçāo ao resto do mundo. Se, por um lado, o positivismo-darwinista-social trouxe problemas teóricos para a intelectualidade brasileira frente à quesıāo da mestiçagem e da problemática da identidade nacional; por oulro lado, deu guarida ao desenvolviménto do

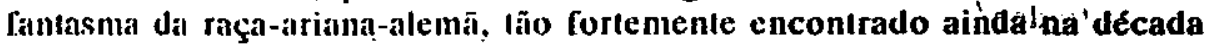
de 1930 no Brasil: "O icleal nacional es na verdade uma utopia a ser realizada no fuluro, ou seja, no processo de branyueamento da sociedade brasileira".

As leiluras teilas das unidades cullurais do Sul do Brasil, ainda hoje, estäo impulsionadas por uma semântica que resultou da ação de significantes que, em grande parte, mantiveram-se vivas por dependerem, fundamentalmente, do não-dilo. Ou seja, nāo roram reveladas nem pelo historiador da cultura regional, nem pelo grupo humano prolagonista de tal história. Isso ocorre, por exemplo, com a leoria racial que, mesmo com suas várias significaçöes (de Gobineau ao Nazismo), concebendo a "desigualdade das raças" humanas de maneira quatitativa, ainda pode ser encontrada no julgamento apologélico do sulista, ençuanto representação-mor brasileira do europeu.

A palinódia melatórica que se consıruiu passou a ser compreendida através de um grande número de denegaçöes que, dado o discurso que se montou, apresentaram-se como ineviláveis. Quando o teuto-brasileiro denega o brasileiro diz nāo ao mestiço baseado no fantas ma da raça. Alravés desle, define sua relação com o Outro, a unidade da pálria-māe com a epopéia colonizadora que, por sua vez. garante imaginariamente a possibilidade de idenlidale à sua comunidade. Cirircularmente, o fantasma reforça a relação de idenlidade com o objelo denegado, no caso, o mestiço. Numa das cenas da operela Der Struwwelpeter de Cesar Bresgen (baseada na obra de Hoffman) encontramos claramente uma lal siluaçāo denegatória. Trata-se da cena quando a personagem "prelo-qual-carvão", c constantemente importunada por oulros três meninos brancos que ficam a caçoar dele por ser preto. $O$ senhor

Antropologin. STo Paulo, 5(1), pp.1.35, 1957. "Wocabulario de Palavres que us descenclentes de culunks alcmies acolhernem na lingun vulgar." IN: Revista de Sociologia.

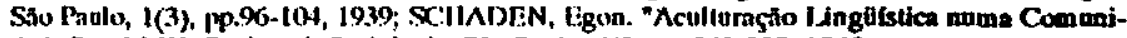
inde Rural." IN: Reitsta de Sociologia. Szo Paulo, 4(3), pp.268-285, 1942 
BAIRON, Sergio. O fantasma th unidade cultural na metáfora patinólica tu brasileiro alemfio.

educador da cena, Seu Nicolau, previne duas vezes os meninos brancos que estāo a caçoar, solicilando que parem de fazé-1o, pois do contrário ameaça castigá-los. Como os meninos não param de zombar, Seu Nicolau agarra as íes crianças brancas e as atira dentro de um tonel de tinla prela. O castigo está cumprido, os Irês meninos brancos ficaram préos! Como na epopéia colonizadora Seu Nicolau diz "não" aos meninos que caçoam do preto. Denega seu "não" ao declarar como cissligo a tez escura aos meninos brancos. Seu Nicolau identifica-se com os meninos brancos quanclo denega o preto. A denegaçĩo age como uma defesa ${ }^{18}$, pois o branco defende-se através da verbalização de uma sensação de desagrado. É necessário locallizar no outro o que é inàceitável nele: o preto, ou scja, a raça inferior. Nolamos que enquanto dependente do discurso fantasmático, a identidade aparece essencialmente confilianle, a ponto de se tornar inconcebível se depender apenas desse discurso ${ }_{r}^{19}$; pois as siguificaçōes yue o fantasma oferece ao desejo representam o suporte necessário que a função imaginária reclama. Unindo imagem especular e desejo, o teulo-brasileiro pocle alucinar a galeria das imagens hislórico-cullurais da idenlilicaç̃̃o narcísica que procura: "O fantasma suporta o desejo e a imagem do outro, sempre envolvida, à cenal ${ }^{20}$.

A saga epopéica dos colonos descendenles de imigrantes alemães está aí. A pátria-mãe está distante. A história estai somente naquele momento em que a pálria-mãe viveu anles da exisłência do sujeilo da saga. A gravura, o desenho ou mesmo a fologralia da pálria-mãe, alimentam uma sensaçĩo de perda do objeto de desejo. Os Iraços mnêmicos fragmentam-se cm imagens dialéticas ${ }^{21}$, o que só possibjlita un reconhecimento da pátria-mãe aos pedaços, como na figura de uma cassa isolada ou numa planficie verde. Ou seja, fantasmagorizou-se a realiclate a a geografia física nino mais delimila a interprelaçĩo da cena. A vanlade parece eslaur no escopo de alcançar a essencia do ser da pítria-mãe. Reconlaecế-la frẹüentemente na suá essência, jamais como alleridade. Sonha-se com cla mas jamilis senle-se a sensaçāo de vivê-la intcirameque. No sonho, a imagem ("velha casa alemã nos verdes

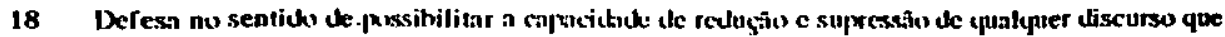
- ameace a identidade súcioncultural do indivichus.

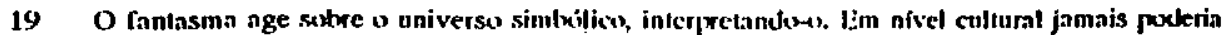
ler uma exislência em-si. Porém, con setr aspecto imaginairiu, ć alravés de fantasma que o leuto-

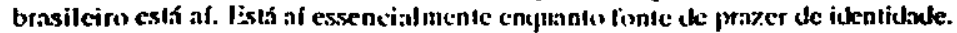

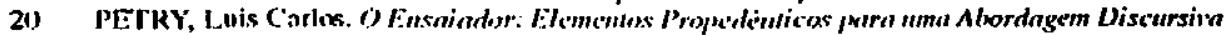

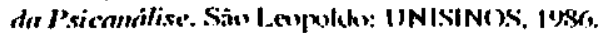

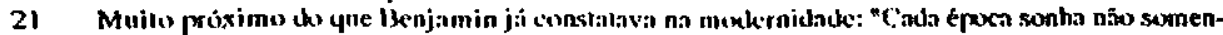
te a seguinte, mas an sınhá-la a lurģa a desperiar." HII:NJAMIN, W. Paris, die IIatpstadt des

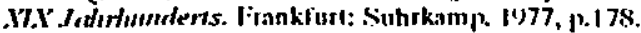


R. Histórta, Săo I'aulo, n. 129-131, p. 19-3), ago.-dez/93 a ago.-cke./94.

prados") é a leslemunhá dál cultura malcrna. No sonho, a imagem é quáse cla, porém, o "quuase" lorna-se, com o passar dos anos, constituinte sarcástico do desejo, pois instilui a inconsequênciá onírica. Ao sonhar com a pátria-mãc, o anseio torna-se somhar a pátria-mãe em sua totalidade ${ }^{22}$.

O teuto-brasileiro recalcou grande parte de sua vivência cultural que the causou desprazer ${ }^{23}$. Podemos pereeber a ruptura que, aos poucos, loi se acirrando entre brasileiro e alemão. O grancle isolamento lingüístico que durante anos ocorreu com a chamada "Colônia Alemä" e os inumeros momentos de exallaçño da "cullura alemā". scguidos de um lorle solapamento do universo simbólico da colónia, articulálos alrávés de uma enorme repressão lingüística que adyuiriu seu auge durante o Eslado Novo, foram falores político-ideológicos que só lïzeram acirrar à consıruçäo narrativa da metáfora do alemão.

A colonização alemã tornou-sc o resultado de medidas e atifudes

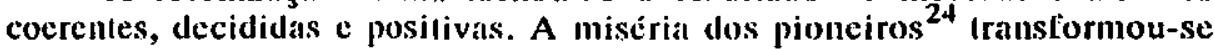
em heroísmo. Os colonos säı objelivos, (lecididos, corajosos e vencedores. No imaginário epopéico, o abandono à própria'sorte $\mathfrak{s}$ una grande consianle marca: - $O$ abandono de yuem escapou da pálria-mãc e nắo voltou mais. $A$ marraliva lembra que o filho jamais vollarai. A epopéia ${ }^{25}$ colonizadora hislória do fitho pródigo que näo volıou. mas que venceu em um novo mundo. Novo, mas não seu, pois o seu mundo continua com a pílria-mãe.

O que se denominou apui a metailora do alemão, $\mathfrak{\text { a }}$ expressão modelar de alemāo consiruída. fundamenlalmente, pelo Deutschimm ao longo dos séculos XIX e XX. Começamos a notar que a região havia passado por un

22 No sunho da ickalizaçîo cullural, o ick:al apmrece de forma lotalizante c nâu fragmentach.

23 Uma análise do recalytie cultural procuramus desenvotver em nossa tese de chuturamento citada ncima.

24 Leitrng zur Geschichte von Nowa P'clripxylis. B3I:RICIITIE. Nowa Petrópolis: Prefeitura Munici-

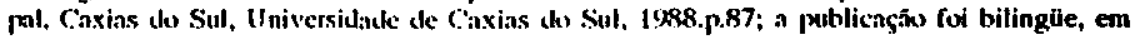
purtuguês c cm Ilunsrïck: Als wir in dieses I.and gekommen sind, hal meine Mutter sich eine Kiste gesetzt und hal angenfangen 7.1 weinen: - Wis ist denn die Kirche? Wo ist die Schule für meine Kincler?".

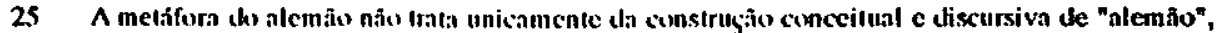
elatworada pelo nacionalismo pressiamo do século passacks. Trata-sc, funchmentalmentc, ch ela-

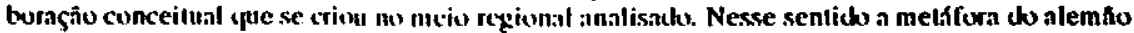

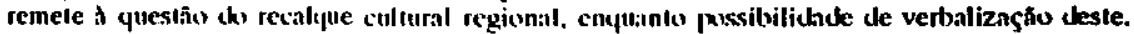

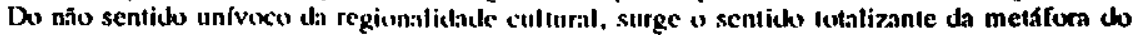

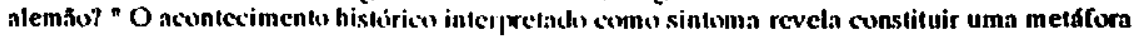
de algo impuxsível de scr diki, cicito de esiruturn, causalidade necessíria, nấo uma contingencia. Tanto Marx cumo lireml consicteram o sintoma como a expressấo de algo que vai alem de um desajuste em si mesino; o lècm cumo efcito de uma legalidack não apreensivel direfamente."

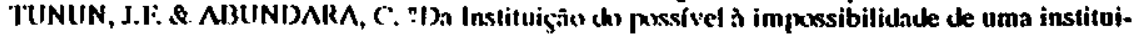

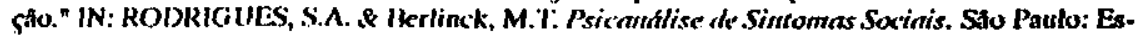
cula, 1988, p.I7.. 
BAIRON, Sérgio. O fantasma th unidade cultural na metáforn palinúklica du brasileiro alemão.

movimento cultural profundamente palinódico que, justamente por ser helerogêneo, necessilou ser negado em vários momentos. Apontando no presente a auséncia da pátria-mãe, suprimiu-se, alravés da ação dos fanlasmas, a morte do mundo material daquela. Foi o falecimento simbólico da pálria-mãe o responsável por um caráter palinódico é comprecnsāo dá cultura da regiāo ${ }^{26}$. O discurso do Grande Outro Epopéico, ou scja, aquele que aponta a vitória do imigrante-colono, é possibilitado pela ausência prescnıc da pátria-mãe. "Alemão", entăo, tornou-se o comando cultural principal à toda rememoração fantasmática. Através da articulação dos fantasmas afirmava-se metaforicamente que nada do que existiu desapareceu, pois o tcuto-brasileiro definiu-se no modelo de alemão sustentado pelo imaginário da epopéja ${ }^{27}$.

O fenômeno do simbólico repelitivo de alemão, conseqüência da sobreposiçāo idealizada de imagens que aparece no.imaginário cullural do teuto-brasileiro, começou a expressar, a partir de determinado momento, uma enorme necessidade de identificaçảo. Mais que isso, Iratou-se de uma expecfativa de reviver a pátria-máe e eliminar a angústia do abandono. Cáda imagem da pátria-mãe, enquanto objelo de desejo perdido, era substituída por uma outra formação imaginária que tenderia, circunstancialmente, diminuir a ansiedade pela identificação. Nesle interim, as manifestaçōes culturais regionais são justamente o mundo menos explorato pelo discurso da metálora do alemão, aparecendo como alvo do discurso elitisı germanista como uma expressāo cullural grotesca, que chamamos a linguagem superlalliva do realismo cotidiano colonial. Esta representa o esyuccimento do esquecimento cultural do Sul do Brasil.

Porém, as conseqüênciás da atuaçāo de discursos germanófilos, transcendem a região do exiremo Sul do Brasil e mesclam-se no senso comum ou mesmo no científico, alé os dias de hoje. Seguindo láis tradiçōes de caráler apofôntico, sabemos que o alemāo traz junto de si uma sćrie de significaçōes

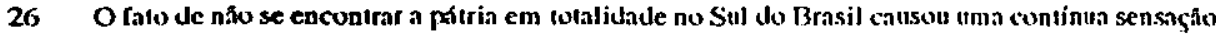
de que ela (p.mfie) havia morrido. Porém, notamos que yuanto mais reforģou-se a sensaçño de

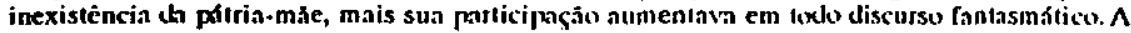

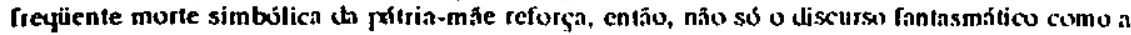
expressĩo (th metáfora do alemâo.

27 Ohjetivando a proposta de discorret sobre a construgäo narrativa ch imaginário cultural, e tendo por base os enunciados acima expustos. cate uma pergunta ceniral: do que é formacho o innginário culturat? Porlemos arriscar uma generalizaç̧o dizendo que sầ imagens à husca de uma realizas̆ono clo desejo. Podemos, igualmente afirmar cule sĩo irngincnlıs de imagens, que por alguma razâo se armazenaram na memória coletiva. Tàis fragmenlix agiram alravés de un esindo

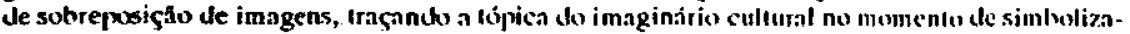

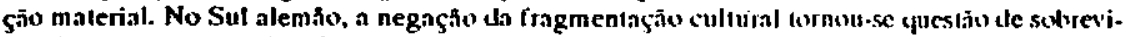
vencia e conservação ta cultura regiunal. 
R. Ilistúrta, Sĩo Paulo, n. 129-131, p. 19-30, ago.-dez/93 a ago.-dez./94.

reducentes de sua enorme diversidade culturat. Geralmente o "alemāo" é apresentado como um indivíduo melódico e altamente organizado ${ }^{28}$. O "alemão" sofre um paradoxo: representa um indivíduo metafísico que se divide entre um ansés idealista de harmonia $e$ a inabalável conviç̧ão de haver nascido para dominar. Esse último sentido é sempre o que prepondera. $O$ "alemão" é apegado à terra, aplicado e competente, o que pode justificar seu sucesso económico. O caráter metódico e sistemático que possui o "alemão" acaba causando um empobrecimento de sua afelividade. Seu lado afetivo, aparece na sua relação com a ciência ou em movimentos de caráter messiânico e fanálico ${ }^{29}$. O desejo do "alemão" estar no Brasil quase sempre não existe, o que parece nos passar a idéia de que cle quase sempre despreza a cultura do outro: faz parle do poder de adaplação dos "alemães" à sua cultura, tão superior e que garante seu equilíbrio racional ${ }^{30}$. A superioridade racial do "alemño" leva à idiotia e à psicastenia. Sua relação sinestésica com o mundo faz seu poder de adaptação tornar-se monotonia ${ }^{31}$. O "alemāonon mantém sua casa limpa, ordenada e ornamentada, porém, essa ordenação é apresentada como signo de esterilidade, assim como seu senso comercial pode, tranqüilamente, chegar às raias do oportunismo inescrupuloso. $O$ "alemāo" é loiro, de olhos azuis, alto e forte, características da raça.

A questāo central está clara: o indivíduo que se intitula "representante da cultura alemã", reconhecendo-se como leulo-brasileiro, carrega estas imagens extremamente conflitantes com as de "brasileiro". Muitas vezes acontece que a rede de significantes que sustenta os significados de "alemão", quando posta ao avesso, sustenta significados de "brasileiro".

Nesse interim, é possível compreender que a consciencia tomada pelo teuto-brasileiro de si, torna seu ser cultural uma grande denegação. Ao identificar-se como teuto, denega o brasileiro e, ao dizer "brasileiro" denega o teulo. Sua "dupla identidade" aprofunda-o numa enorme crise com seu universo simbólico. A necessidade de repelir os significados de "alemão" simboliza, prioritariamenle, uma falta presente. Através da articulação dos fanlasmas, a perda do objelo de desejo tornou-se mais suportável, percurso imaginário fundamental na construção das significaçōes culturais da regiāo.

28 Comu Elza em Amar, Verlo Intrmisitivo de Mário de Antracle.

29 Como o julgamentu da seita "Muckers". Ver PETRY, Leopoldo. O Episódio do Ferrabraz. Os Muckers. Sĩo Leopoldu: Rotermund, 1966.

30 Maniquefsmo culıural aprofunchdo apis a "campanha naciunalizaciora" de Vargas durante o Es. taclo Novo.

31 O universo sinstúlico yue aindo na década de 1930 era iuentificado apologeticamente como "alemâu", passou a ser identificacto na décactn de 1940 como "brasileiro", o que deveria acontecer, pacilicamente, ou nึึ. 
BNIRON, Sergio. O fantasma da uniulicte cullural na metsfora palinúdica do bonsileiro alemâo.

Chegámos assim, à compreensāo que aponla a epopéia da colonização como presença denegada de significaçóes esquccidas e recalcadas. Colónia Alemā significa, acima de ludo, uma colonizaçäo imaginária, levada a efcilo pelos mais variados discursos germisıs e nacionalisıas brasileiros. Colónia Alemã é, essencialmente, discurso!

ABSTRAC:T: The phantom of cultural unily in the mlinodic metaphor of Brazitian Germans is presented as an understanding of "Europenn culture" in southern Brazil. The belief that a Germany or Italy was recreated in microregions in Brazil is still clearly present al the end of this century. The current challenge for an unclerstanding of this histury covers two controversial issues. On one side, a cullural psychoanalysis, which may make an explomition of psychoanniysis as a langunge theory possible as a North-American culturalist project. On the other hand, a hermeneutical culture which has as purpose the identification of universal meanings and is present in such regions. This article luesn't fil inlo the obscure paths of the currenl llistory of Mentalities in regard to Psychoanalysis or to a hermeneutical culture.

KEY-WORDS: phantom, melaphor, palinodic, uther, dencgation. 